\title{
Auditing Revenue Assurance Information Systems for Telecom Operators
}

\author{
Peirong Che ${ }^{1}$, Zhaokun $\mathrm{Bu}^{2}$, Rui $\mathrm{Hou}^{3}$ and Xinxing $\mathrm{Shi}^{1}$ \\ ${ }^{1}$ School of Economics and Management, Beijing University of Posts and \\ Telecommunications, Beijing 100096, P.R. China chepeirong@buptinfo.com \\ ${ }^{2}$ China Unicon, No.133, XiDanBeiDaJie, XiCheng District, Beijing 100032, P.R. China \\ bzk75@sina.com \\ ${ }^{3}$ China Telecom, NO.31, jinrong dajie, Beijing 100032, P.R. China \\ rayhou@vip.sina.com
}

\begin{abstract}
Auditing revenue assurance information system is a hot topic because of its importance to the telecom operators ant its auditing difficulties. In this paper, first, the scope of the revenue assurance information system of telecom operators is prescribed. Second, it is to advance the IT audit framework of telecom operators based on the COSO and COBIT framework and the method of application audit for the China telecom operators based on the revenue-generated business process and risk assessment. Finally, it is pointed out that the weaknesses that have been found during the process of auditing.
\end{abstract}

Keywords: Audit, Revenue assurance information system, Business process, Telecom operators

\section{INTRODUCTION}

With the development of high speed for several years, China telecom industry has entered a relatively stable developing period of low speed. Due to the intensification of competition, it is important increasing for the telecom operators to tap the potentialities for increasing income within the current service and customer range. Moreover, four major telecom operators of China have entered into capital market in the U.S. successfully, thus, they should be restrained by the related laws of the U. S, especially the Sarbanes-Oxley Act (SOX)[1]. Therefore, the revenue assurance information system audit, being one of the most direct and effective approaches for looking for income loophole and reducing income loss, comes into the agenda gradually. 


\section{THE AUDIT TO THE REVENUE ASSURANCE INFORMATION SYSTEM OF THE TELECOM OPERATORS}

\subsection{The Range of the Revenue Assurance Information System}

Which information system of the telecom operator relates to the revenue assurance? In practice, these systems include data collection system, billing system, settlement system, and operation and account system.

1) Data collecting system: The system collects the subscriber's original data and information of their usage to the network from the telecom infrastructure network (i.e. switch, gateway).

2) Billing system: The billing fee is calculated according to the subscriber's usage to the network and the pre-determined principles and regulations. It provides the basis for payment.

3) Settlement system: It supports the settlement among the telecom operators, includes roaming settlements and interconnecting settlements.

4) Operation and account system: The operating system is used to handle the service application from the subscribers. The account system is used to generate the final monthly billing sheet to provide the basic data to financial report.

\subsection{Combination of COSO, COBIT and the Company's Financial Report}

COSO provides a view point for an extensive internal control at the enterprise level [2]. However, COSO does not concentrate on IT, while COBIT provides the guide for assessing the internal control of IT technique for supporting enterprise target [3].

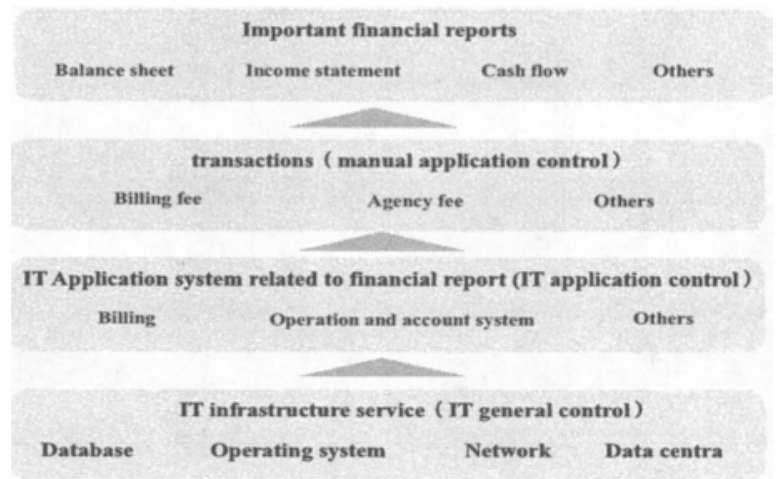

Figure 1. Combination of COSO, COBIT and the Company's Financial Report 
COBIT is a general IT governance framework, which considers not only about the financial report internal control target, but also about the non-financial report internal control target, such as the effect and the efficiency of the information, and the control processes, such as information framework, technical trends etc. However, the attention of Sarbanes-Oxley Act is how to make the financial report process have an existing and inherent reliability. Thus, if the COBIT frame and target are to be applied into Sarbanes-Oxley Act, a connection must be set up between COBIT target and financial report assertion.

As shown in Fig.1 above, the important financial reports are based on the important business processes (transactions) related to the financial report items, while the information system is connected with the financial report through the transactions. Currently, the remedies made by china telecom operators for Sarbanes-Oxley Act compliance mainly concentrate on the control transactions, for IT, it mainly includes the IT general control for the IT basic infrastructure and the IT application control for the related transactions.

Currently, there are many contributions on general control, and therefore, it would not be discussed in this paper.

\subsection{The Application Audit of the Revenue Assurance Information System}

According to the requirements of the Sarbanes-Oxley Act, the IT application audit of the telecom operators concentrates on the following important issues:

1) The identification of the business processes(transactions)

2) The identification of the key application control

3) The matching of the business process(transaction) and the key application control

\subsubsection{The Identification of the Key Business Process (Transaction)}

The revenue assurance system of the telecom operator includes the following ten key business processes:

1) Open an account: This describes the procedure of subscriber's opening an account in a service hall, from a subscriber's request at the hall, to printing return receipt, subscriber's confirmation with a signature, and keeping a copy of valid ID card, where there is always the risk of incomplete subscriber information.

2) Credit control: This describes the procedure of managing subscriber's credit, from the subscriber's application for activation or inactivating a postpaid subscriber at the end of the month, to the authorization of credit to a subscriber or a postpaid subscriber's inactivation at the end of the month, where there might be the risk of incorrect amount of credit being authorized.

3) Call detail record (CDR) collection and format: This describes the procedure of generating original CDR, where there might be the risk of CDR loss or illegal modification.

4) The first-stage rating: This describes the procedure of first-stage rating CDR, where there might be the risk of inaccurate computing. 
5) Roaming process: this describes the procedure of roam-in CDR sorting and uploading, roam-out $\mathrm{CDR}$ reception, where there might be the risk of incomplete and/or delayed roaming CDR.

6) The second-stage rating: This describes the procedure of the second-stage discount, according to the subscriber's information, to the different standard rate, where there might be the risk of delayed update of service package information.

7) Bill discount: This describes the procedure of executing monthly bill discount, where there might be the risk of inaccurate computing.

8) Billing: This describes the procedure of monthly billing, where there might be the risk of inaccurate monthly revenue report.

9) Payment: This describes the procedure of subscriber's paying bill at the service hall, where there might be the risk of repeated processing of bill.

10) Settlement: This describes the procedure of inter-network settlement, where there might be the risk of incorrect settlement.

\subsubsection{The Identification of the Key Application Control}

IT Application control concentrates on the design of the input control, processing control and output control to the information system. The following ten types of the application control are usually adopted by the telecom operators.

A. Edit verify, validity verify: For example, in an operation and account system, the data is inputted by the front-desk operators, and then the compile verification was done by the system automatically to verify the validity of the data.

B. Logical relationship verify: Such tests include range, restriction, character types and rationality tests. Fox example, the integrated operation and account system identifies the logical relationship(the equipment number must have 11 digits) automatically between the account opening data spoken by the subscribers and that inputted by the front- desk operators, the data fell short of regulations are rejected.

C. Configurable parameter control: For example, the switch detect its storage capacity automatically and the switch will delete the billing sheet which have been gathered by the billing system before it reaches the predetermined threshold ( $60 \%$ of the total capacity) in order to avoid the overflow of the data.

D. Key control reports: The key control reports are those that generated or depend on by the system itself, which are used for data comparison or data checking.

E. System examining and approve: There are some examining and approving programs in the system.

F. Separation of the incomparable duty: The incomparable duties are done by different persons.

G. Service authorization: Service authorization should comply with leastauthorizing principle.

H. Abnormal report: Abnormal reports are provided.

I. Data transmission or interface control: For example, the receiver checks the number of bytes or records received using the relevant information the transmitter sends, to make sure the record is not disrupted during transmission. 
J. Automatic calculation: For example, billing fee is computed automatically.

\subsubsection{The Matching of the Key Business Process (Transaction) and the Key Application Control}

The tablel describes the matching between the key business processes and the key application controls.

Table 1. The matching of the key business process (Transaction) and the key application Controls (numbers (i.e.1, 2,..., 10) and Letters(i.e. A,B,..., J) represent the key business processes and key application control respectively, according to the section 2.3.1 and 2.3.2)

\begin{tabular}{|c|c|c|c|c|c|c|c|c|c|c|}
\hline key Application Control & 1 & 2 & 3 & 4 & 5 & 6 & 7 & 8 & 9 & 10 \\
\hline A & $\checkmark$ & & & & & & & & & \\
\hline B & $\checkmark$ & & $\checkmark$ & $\checkmark$ & $\checkmark$ & $\checkmark$ & $\checkmark$ & $\checkmark$ & $\checkmark$ & $\checkmark$ \\
\hline $\mathrm{C}$ & & & $\checkmark$ & $\checkmark$ & & & & & & $\checkmark$ \\
\hline D & & & $\checkmark$ & & & & & & & \\
\hline E & & & & & & & & & $\checkmark$ & \\
\hline F & & & & & & & & & & \\
\hline G & $\checkmark$ & $\checkmark$ & & $\checkmark$ & & $\checkmark$ & $\checkmark$ & & $\checkmark$ & $\checkmark$ \\
\hline $\mathrm{H}$ & & $\checkmark$ & $\checkmark$ & & $\checkmark$ & $\checkmark$ & & & & \\
\hline I & $\checkmark$ & $\checkmark$ & & $\checkmark$ & $\checkmark$ & $\checkmark$ & & $\checkmark$ & & $\checkmark$ \\
\hline $\mathbf{J}$ & & $\checkmark$ & & $\checkmark$ & & & $\checkmark$ & & & $\checkmark$ \\
\hline
\end{tabular}

\subsection{The Weaknesses Found during the Process of Auditing}

The following several types of weakness are found during the processes of auditing:

1) The shortage of system automatic control

2) The shortage of system-based manual control

3) The manual control was not executed effectively

4) The description of the transactions is not consistent with the current control measures

Hence, the auditing will be an on-going process until all the requirements should be met.

\section{CONCLUSIONS}

Sarbanes-Oxley Act is not only a challenge but also an opportunity to the China telecom operators. Telecom operators can improve its internal management by using such opportunity. Hence, based on the COSO and COBIT, the range and the methods have been proposed to audit the revenue assurance system, including the identification of the key business processes, the identification of the key application 
control and their matching. Such proposal can give some reference to the audit of revenue assurance system of China telecom operators.

\section{REFERENCES}

1. The Sarbanes-Oxley Act of 2002, Strategies for Meeting New Internal Control Reporting Challengers (Pricewaterhouse Coopers, 2003).

2. The Committee of Sponsoring Organizations of the Treadway Commission, Internal Control Integrated Framework (the COSO report) (USA, 1992).

3. Information System Audit and Control Association, Control Objectives for Information and related Technology (COBIT) (Rolling Meadows, Illinois, USA, 2000). 